\title{
Prevalence of Hyponatremia in Children with Pneumonia -Cross- Sectional Study
}

\author{
Rahul V, Jose O \\ *Junior Resident Govt T D Medical College Alappuzha \\ **Associate Professor Govt T D Medical College Alappuzha
}

\begin{abstract}
Pneumonia remains the leading single cause of childhood mortality. It's associated with several complications and the commonest metabolic complication being hyponatremia. Studies done in the western countries have reported a high prevalence of hyponatremia, an indicator of disease severity. No study has been done to evaluate the prevalence of hyponatremia in children in kerala

Objectives : The objectives of this study were; 1, Determine the prevalence of hyponatremia in children aged two months to twelve years admitted with pneumonia at TDMC Alappuzha. 2, Describe selected sociodemographic and clinical characteristics of children with hyponatremia. 3,Determine the association of hyponatremia and severity of pneumonia.

Methodology: A descriptive cross-sectional study was carried out at TDMC ALAPPUZHA on children aged 2 months to 12 years admitted with pneumonia. Those who met the inclusion criteria were recruited. History and physical examination was done to confirm diagnosis and classify the severity of pneumonia. A $2 \mathrm{ml}$ blood sample was then withdrawn from the patient and taken to the laboratory for electrolyte analysis.

Results: A total of 100 pediatric patients admitted at TDMC were reviewed. Prevalence of hyponatremia was $6 \% \%(6 / 100)$.. Hyponatremia was significantly associated with ICU admission(p=0.009).hyponatremia was significantly associated with increased number of ICU days $(p=0.001)$.There was a no significant association between severity of pneumonia and hyponatremia $(p=0.083)$. No association could be obtained between factors like acute phase reactants, age,sex,choice for higher antibiotics

Conclusion: Hyponatremia at admission is more associated with icu admission. .There is a no high prevalence of hyponatremia in children admitted with pneumonia at TDMC. Hyponatremia is not an indicator of severe illness
\end{abstract}

Keywords : hyponatremia , pneumonia

\section{Introduction}

Pneumonia remains the leading single cause of childhood mortality. Its accounts for $16 \%$ ( 920 136) of all under five deaths. . Pneumonia affects children and families everywhere, but is most prevalent in South Asia and sub-Saharan Africa where its account for $85 \%$ of deaths.India has a mortality rate of 322 per 100000 underfive population

Despite the various strategies put in place to curb this disease (vaccination, vitamin A and zinc supplementation, exclusive breastfeeding for six months, early detection and treatment e.t.c), prevention and treatment remains a challenge. Most children with pneumonia can be treated safely at home. However studies done have shown that only $27 \%$ of these children actually get the appropriate treatment [1].Failure to institute timely treatment results in progression of the disease necessitating hospitalization. Children admitted with pneumonia are critically ill and often times have complications which include electrolyte abnormalities, the commonest being hyponatremia. Studies done in the western countries have shown up to $45.4 \%$ of children hospitalized with pneumonia had hyponatremia (2-4).

Hyponatremia in pneumonia has been linked to the syndrome of inappropriate secretion of antidiuretic hormone (SIADH) (5). ADH excess results in water retention and volume expansion leading to fall in Serum osmolality below the reference range. Hyponatremia does not develop unless the patient is ingesting or receiving some source of free water. Most children with pneumonia cannot maintain adequate fluid intake due to breathlessness, fatigue, or risk of aspiration (6) necessitating fluid therapy. Administration of hypotonic fluids may lead to development of acute hyponatremia which leads to a rapid shift of fluids into brain cells $(16,20)$. The resultant cerebral edema is associated with high mortality. Hyponatremia has also been documented as a marker of severe illness and increases mortality $(7,8)$. It's therefore paramount for clinicians to understand common electrolyte abnormalities, have a high index of suspicion and timely recognize them. This will facilitate institution of appropriate treatment resulting in better outcomes. 
Aim

What is the prevalence of hyponatremia in children aged two months to twelve years admitted with severe pneumonia at TDMC Alappuzha and to determine the association of hyponatremia and severity of pneumonia.

\section{Materials And Method}

Study Design :This was a descriptive cross-sectional study

Study Site :The study was carried out at TDMC Alappuzha, paediatric icu and paediatric wards.

Study Population :Children aged two months to twelve years admitted at TDMC Alappuzha with a diagnosis of pneumonia

Sample Size: 100

\section{Sampling Procedure}

Patients were identified by the principal investigator at the Paediatric casuality,icu and the wards during the day, complete history and physical examination was then done to confirm diagnosis. If a child met the inclusion criteria, informed consent was sought from the guardian or the parent after explaining to him or her about the study.

Socio-demographic data and clinical characteristics of each patient were captured in the questionnaire. Clinical characteristics included axillary temperature and respiratory rate were also taken. Patients were then categorized into either having severe or very severe pneumonia based on the WHO classification.

Using aseptic technique, $2 \mathrm{mls}$ of blood was withdrawn from the antecubital fossa of each patient during admission and after 48 hours. The blood samples were then transported to the central laboratory within an hour of collection for analysis of complete blood cell count,erythrocyte sedimentation rate (ESR), C-reactive protein (CRP), serum concentrations of sodium $(\mathrm{Na})$, urea, creatinine

\section{Inclusion Criteria}

1. Children 2 months to 12 years admitted at TDMC alappuzha with a diagnosis of pneumonia.

2. All children for whom consent is obtained from parent(s) or legal guardian(s) to participate in the study.

\section{Exclusion Criteria}

1. All children with pneumonia and diarrhea .Diarrhea is associated with electrolyte abnormalities.

2. All children with known renal disease. Patients with renal disease have fluid retention which results in dilutional hyponatremia.

3. All children with a known cardiac disease which results in volume overload leading to dilutional hyponatremia.

4. All children whose parent(s) or guardian(s) refuses to give consent.

Statistical Analysis: Appropriate statistical software will be used for analysis.

Ethical Considerations: Permission to conduct the study will be obtained from institutional research committee and ethical committee of TDMC

\section{Result}

In this study of 100 children, majority belonged to the age group 1-5 yrs (52\%), whereas $32 \%$ belonged to $2 \mathrm{~m}$-1year age group and $16 \%$ belong to 5-12 years age group. Out of 100 children, 56 were males (56\%) and 44 were females (44\%).out of 10075 patients diagnosed to have simple pneumonia, 23 patients diagnosed to have severe pneumonia and 2 patients with very severe pneumonia. At admisssion hyponatremia seen in 7 patients and at $48 \mathrm{hr}$ after admission hyponatremia seen in only 6 patients.there is no statical significance obtained between presence of hypontremia both at admisssion and at $48 \mathrm{hr}$ after admission with severity of pneumonia(16\%;p=0.083) , acute phase reactants(CRP:7.8\%,p-0.413,ESR:6.1\%\%,p-0.363) and age of the child.,choice of antibiotics, and number of hospital days.statistical significance obtained between hyponatreimia at admission and increased ICU admissions(17.9\%,p-0.000) and increased number of days(>2days) in icu(p$0.001)$ 


\begin{tabular}{|c|c|c|c|c|c|c|c|}
\hline \multirow[t]{3}{*}{ Hyponatremia } & & \multicolumn{4}{|c|}{ Diagnosis } & \multirow{3}{*}{2} & \multirow{3}{*}{$\mathrm{P}$} \\
\hline & & \multicolumn{2}{|c|}{ Pneumonia } & \multicolumn{2}{|c|}{$\begin{array}{c}\text { Severe/Very severe } \\
\text { pneumonia }\end{array}$} & & \\
\hline & & Count & Percent & Count & Percent & & \\
\hline \multirow{3}{*}{$\begin{array}{l}\text { Sodium level at } \\
\text { admission }\end{array}$} & Normal & 71 & 94.7 & 20 & 80.0 & \multirow[t]{3}{*}{4.97} & \multirow[t]{3}{*}{0.083} \\
\hline & Hyoponatremia & 3 & 4.0 & 4 & 16.0 & & \\
\hline & Hypernatremia & 1 & 1.3 & 1 & 4.0 & & \\
\hline \multirow{3}{*}{$\begin{array}{l}\text { Sodium level at } \\
48 \mathrm{hr} \text { of } \\
\text { admission }\end{array}$} & Normal & 69 & 92.0 & 22 & 88.0 & \multirow[t]{3}{*}{0.37} & \multirow[t]{3}{*}{0.833} \\
\hline & Hyoponatremia & 4 & 5.3 & 2 & 8.0 & & \\
\hline & Hypernatremia & 2 & 2.7 & 1 & 4.0 & & \\
\hline
\end{tabular}

Association of hyponatremia and diagnosis

\begin{tabular}{|c|c|c|c|c|c|c|c|}
\hline \multirow{3}{*}{ Investigations } & & \multicolumn{4}{|c|}{ Sodium level at admission } & \multirow{3}{*}{2} & \multirow{3}{*}{$\mathrm{p}$} \\
\hline & & \multicolumn{2}{|c|}{ Normal } & \multicolumn{2}{|c|}{ Hyoponatremia } & & \\
\hline & & Count & Percent & Count & Percent & & \\
\hline \multirow[t]{2}{*}{ CRP } & Positive & 83 & 92.2 & 7 & 7.8 & \multirow{2}{*}{0.67} & \multirow{2}{*}{0.413} \\
\hline & Negative & 8 & 100.0 & 0 & 0.0 & & \\
\hline \multirow[t]{2}{*}{ ESR } & Positive & 77 & 93.9 & 5 & 6.1 & \multirow{2}{*}{0.83} & \multirow{2}{*}{0.363} \\
\hline & Negative & 14 & 87.5 & 2 & 12.5 & & \\
\hline \multirow[t]{2}{*}{ Total count } & Normal & 13 & 100.0 & 0 & 0.0 & \multirow{2}{*}{1.15} & \multirow{2}{*}{0.283} \\
\hline & High & 78 & 91.8 & 7 & 8.2 & & \\
\hline \multirow{2}{*}{$\begin{array}{l}\text { Type of fluid } \\
\text { intake }\end{array}$} & Oral & 91 & 93.8 & 6 & 6.2 & \multirow[b]{2}{*}{$13.13 * *$} & \multirow[b]{2}{*}{0.000} \\
\hline & IVF & 0 & 0.0 & 1 & 100.0 & & \\
\hline
\end{tabular}

Table Association of sodium level at admission and treatment.

\begin{tabular}{|c|c|c|c|c|c|c|c|}
\hline \multirow{3}{*}{ Treatment } & & \multicolumn{4}{|c|}{ Sodium level at admission } & \multirow{3}{*}{2} & \multirow{3}{*}{$P$} \\
\hline & & \multicolumn{2}{|c|}{ Normal } & \multicolumn{2}{|c|}{ Hyoponatremia } & & \\
\hline & & Count & Percent & Count & Percent & & \\
\hline \multirow[t]{2}{*}{ ICU admission } & Present & 23 & 82.1 & 5 & 17.9 & \multirow{2}{*}{$\begin{array}{c}6.78^{*} \\
*\end{array}$} & \multirow{2}{*}{0.009} \\
\hline & Not & 68 & 97.1 & 2 & 2.9 & & \\
\hline \multirow[t]{3}{*}{ Days in ICU } & No ICU & 68 & 95.8 & 3 & 4.2 & \multirow{3}{*}{$\begin{array}{c}14.67 \\
* *\end{array}$} & \multirow{3}{*}{0.001} \\
\hline & $<2$ days & 23 & 88.5 & 3 & 11.5 & & \\
\hline & $>2$ days & 0 & 0.0 & 1 & 100.0 & & \\
\hline \multirow{2}{*}{$\begin{array}{l}\text { Days of hospital } \\
\text { stay }\end{array}$} & $<5$ days & 82 & 94.3 & 5 & 5.7 & \multirow{2}{*}{2.28} & \multirow{2}{*}{0.131} \\
\hline & $>5$ days & 9 & 81.8 & 2 & 18.2 & & \\
\hline \multirow[t]{2}{*}{ Antibiotic } & Baseline & 82 & 94.3 & 5 & 5.7 & \multirow{2}{*}{2.28} & \multirow{2}{*}{0.131} \\
\hline & Highier & 9 & 81.8 & 2 & 18.2 & & \\
\hline
\end{tabular}

**: - Significant at 0.01 level, *: - Significant at 0.05 level

\section{Discussion}

Hyponatremia has been shown to be the commonest electrolyte abnormality in hospitalized patients. Its complicates many conditions including respiratory, central nervous system, malignancies e.t.c and it's a marker of severe illness resulting in high mortality and morbidity The purpose of our study was to find if hyponatremia was commonly seen in children with pneumonia and also to investigate a possible correlation between the hyponatremia as measured by serum sodium level and the severity of pneumonia symptoms according to who guidelines. This study was a descriptive cross sectional study done in children diagnosed to have pneumonia as per the WHO ARI guidelines at the Pediatrics ward and PICU at Government T. D. Medical College, Alappuzha.The overall prevalence of hyponatremia was 5\%. This rate was 5.4 times lolwer than that reported in similar studies elsewhere. In a previous Indian study a study done by S.D.Subba Rao et.al, the prevalence of hyponatremia was $27 \%$ which is 5.4 times lower than that found in the current study ${ }^{2}$. In recent study done in Kenya national hospital study, the prevalence of hyponatremia is $71 \%$ which is 14.2 times higher than this study. These findings could be attributed to the fact that the use more hyponatremic fluids for the management for severe pneumonia.

In my study children with severe pneumonia is $25 \%$.there is no correlation between the prevalence of hyponatremia in severe and very severe pneumonia is low as $16 \%(\mathrm{p}=0.083)$. In previous study done at kenya national hospital children with very severe pneumonia were more likely to have hyponatremia a proportion of $81.8 \%$ compared to those with severe pneumonia (59.7\%). A significant association between very severe pneumonia and hyponatremia $(\mathrm{p}=0.002)$ was observed. This may be due to the more use of hyponatremic fluids for initial treatment,as well as the poor nutrional status of the children there. 
In our study the children admitted in PICU with severe pneumonia and hyponatremia is $17.9 \%$ $(\mathrm{p}=0.009)$ is significant,and they had more number of days(>2days) in icu setting $14.67 \%(\mathrm{p}=0.001)$,significant .Studies have also demonstrated that, respiratory compromise is a cormorbid factor in patients with hyponatremia markedly increasing the risk of death from pneumonia[35-37]. The underlying mechanism is probably hypoxia, a major risk factor for the development of hyponatremic encephalopathy(38). Studies of hyponatremic animals have revealed that hypoxia impairs volume regulation of brain cells, decreases cerebral perfusion, and increases the probability of neuronal lesions developing (39). Adaptation of the brain to hyponatremia largely depends on extrusion of sodium from the intracellular space via sodium-potassium ATPase pumps. This energy-dependent process is impaired under hypoxic conditions. The combination of systemic hypoxia and hyponatremia is more deleterious than is either condition alone, because hypoxia impairs the ability of the brain to adapt to hyponatremia, worsening hyponatremic encephalopathy (40).

Although the study was not powered for analysis of hospital acquired hyponatremia due to the low numbers of children who had treated with iv fluids . It was also observed that children who received intravenous fluids were more likely to develop hyponatremia compared to those who were on oral fluids $50 \%(\mathrm{p}=0.009)$. This could be attributed to the fact that the commonest fluid given was Half Strength isolyte-p, a hypotonic fluid. Studies have shown that use of hypotonic fluids is associated with development of hyponatremia which has a poor outcome $(5,30,31)$.These observations supports the fact that the main cause of hyponatremia in pneumonia is SIADH(). In SIADH the release of ADH is not inhibited by a reduction in plasma osmolality when the individual ingests water and the osmolality of the plasma drops. As the main solute of plasma is sodium, this hypoosmolar state is usually detected as a low sodium level on laboratory testing. SIADH is therefore primarily a condition that results in the abnormal handling of water loading and not a problem with excessive solute loss. This is why it is usually treated with fluid (in particular water) restriction in our study we couldn't find any correlation between acute phase reactants and hyponatremia at admission.

\section{Conclusion}

Our study did not find an increased prevalence of hyponatremia in children with pneumonia. It also did not find any significant correlation between the severity of pneumonia and the serum sodium levels. But we could find a significant correlation between hyponatremia at admission and the prolonged days of icu admission. We also couldn't find a correlation between hyponatremia and acute phase reactants at admission

\section{Limitations}

The study did have several limitations. First of all, the sample size was very small hence evidence based on this study cannot be extrapolated to a larger population. Another major limitation was the lack of a control group.we didn't consider the aetiology of hyponatremia at admission like nutrional status of the child

\section{Recommendation}

Closely monitor serum electrolyte level in patients admitted in PICU, as well as who was getting iv fluids.also avoid hypotonic fluids in children with pneumonia

\section{References}

[1]. Wardlaw, Tessa M.; Johansson, Emily White; Hodge, Matthew; World Health Organization; UNICEF. Pneumonia: the forgotten killer of children

[2]. S.D.Subba Rao, Biju Thomas. Electrolyte abnormalities in children admitted to pediatric intensive care unit. Indian Pediatr.2000; 37:1348-1353.

[3]. Prasad SV, Singhi S, Chugh KS. Hyponatremia in sick children seeking pediatric emergency care. Indian Pediatr. Mar 1994:31(3):287-94.

[4]. Singhis, Dhawan A. frequency and significance of electrolyte abnormalities in pneumonia. Indian Pediatr.1992 Jun; 29(6):735-40

[5]. Rivers PAR, Forsling LM, Olver PR. Inappropriate secretion of antidiuretic hormone in infants with respiratory infections. Arch Dis Child 1981, 56:358-363.

[6]. Khoshoo, V, Edell, D. Previously healthy infants may have increased risk of aspiration during respiratory syncytial viral bronchiolitis. Pediatrics 1999; 104:1389.

[7]. Kazumari Kaneko, Ken ichiro kaneko. Hyponatremia in children with respiratory tract infections. Pediatr Nephrol (2009) 24:1595.

[8]. Massimiliano Don, Giuliana Valeria. Hyponatremia as a marker of invasiveness of pediatric respiratory tract infections. Pediatr Nephrol 8:1597-1598.

[9]. Fine MJ, Hanusa BH, Lave JR, et al. (1995) Comparison of a disease-specific and a generic severity of illness measure for patients with community-acquired pneumonia. J Gen Intern Med 10:359-368.

[10]. Rose, BD, Post, TW, Clinical Physiology of Acid-Base and Electrolyte Disorders, 5th ed,McGraw-Hill, New York, 2001, pp. 699716. Adrogue, HJ, Madias, NE

[11]. Hyponatremia. N Engl J Med 2000; 342:1581.

[12]. Hoorn EJ, Geavy D, Robb M, Halperin ML, Bohn D. Acute Hyponatremia related to intravenous fluid administration in hospitalized children. Pediatrics, 2004; 113:1279-1284.

[13]. Moritz ML, Ayus JC. Preventing neurological complications from dysnatremias in children. Pediatr Nephrol 2005; 20:1687-1700.

[14]. Ayus JC, Achinger SG, Arieff A. Brain cell volume regulation in hyponatremia: role of sex, age, vasopressin, and hypoxia. Am J Physiol Renal Physiol. Sep 2008;295(3):F619-24. 
[15]. Sarnaik AP, Meert K, Hackbarth R, Fleischmann L. Management of hyponatremic seizures in children with hypertonic saline: a safe and effective strategy. Crit Care Med. 1991; 19:758-1762.

[16]. Bruce RC, Kliegman RM. Hyponatremic seizures secondary to oral water intoxication in infancy: association with commercial bottled drinking water. Paediatrics. 1997; 100:E4.

[17]. Don M.Valerio, G Korppi et al. Hyponatremia in pediatric community acquired pneumonia. Pediatr Nephrol. 2008; 23(12):22472253.

[18]. Marya D Zilberberg, Alex Exuzides, James Spalding, Aimee Foreman, Alison Graves Jones, Chris Colby, and Andrew F Shorr. Hyponatremia and hospital outcomes among patients with pneumonia: a retrospective cohort study.

[19]. Asadollahi K, Beeching N, Gill Hyponatremia as a risk factor for hospital mortality. QUMed. 2006; 99:877-80

[20]. Hawkins RC. Age and gender as risk factors for hyponatremia and hypernatremia. Clin ChimActa. Nov 2003; 337(1-2):169-72.

[21]. Hoorn E, linermans J, Zietse R. Hyponatremia in hospitalized patients, epidemiology, etiology and symptomatology. J Am Soc Nephrol. 2004; 15:561(A)

[22]. Carey RG, Bucuvalas JC, Balistreri WF, Nick TG, Ryckman FR, Yazigi N. Hyponatremia increases mortality in pediatric patients listed for liver transplantation. Pediatr Transplant. Feb 202009.

[23]. Rey C, Los-Arcos M, Hernández A, Sánchez A, Díaz JJ, López-Herce J. Hypotonic versus isotonic maintenance fluids in critically ill children: a multicenter prospective randomized study.Acta Paediatr. Aug 2011; 100(8):1138-43.

[24]. Ellison DH, Berl T. Clinical practice. The syndrome of inappropriate antidiuresis. N EnglJMed. May 17 2007; $356(20): 2064-72$.

[25]. Gonzalez CF, Finberg L, Bluestein DD. Electrolyte concentration during acute infections.Amer J Dis Child 1964, 107: 476-482.

[26]. World Health Organization. Acute respiratory tract infections in children. Case managementin small hospitals in developing countries. WHO/ARI/905.

[27]. Lussky Ho, Friedstein H. water retention in pneumonia. Amer Dis Child 1920, 19:337-343.

[28]. Sunderman FW, Austin JW, Camac JG. Studies in serum electrolytes: concentration of electolytes in serum during lobar pneumonia. J clin invest 1926, 3:37-64.

[29]. Stormant JM, Waterhouse C:severe hyponatremia associated with pneumonia.Metabolism1962,11:1181-1186.

[30]. Shann F, Germer S;Hyponatremia associated with pneumonia or bacterial meningitis. ArchDis Child 1985, 60:963-966.

[31]. Dreyfuss D, Leviel F, Paillard M, et al. Acute infectious pneumonia is accompanied by a latent vasopressin-dependent impairment of renal water excretion. Am Rev Respir Dis 1988;138:583-589.

[32]. Leach RM, Forsling ML. The effect of changes in arterial PCO2 on neuroendocrine function in man. Exp Physiol 2004;89:287-292.

[33]. Palin K, Moreau ML, Sauvant J, et al. Interleukin-6 activates arginine vasopressin neurons in the supraoptic nucleus during immune challenge in rats. Am J Physiol Endocrinol Metab. 2009;296:E1289-E1299.

[34]. Sterns RH. Treating hyponatremia: why haste makes waste.South Med J. 1994Dec;87(12):1283-7

[35]. Arieff AI, Ayus JC, Fraser CL. Hyponatraemia and death or permanent brain damage in healthy children. BMJ.1992;304 :12181222.

[36]. Sgouros S, Goldin JH, Hockley AD, Wake MJ, Natarajan K. Intracranial volume change in childhood. J Neurosurg. 1999;91:610616.

[37]. Xenos C, Sgouros S, Natarajan K. Ventricular volume change in childhood. J Neurosurg. 2002;97:584-590.

[38]. Nzerue C et al. (2002) Predictors of mortality with severe hyponatremia. J Am Soc Nephrol 13: A0728.

[39]. Halberthal M, Halperin ML, Bohn D. Acute hyponatraemia in children admitted to hospital: retrospective analysis of factors contributing to its development and resolution. BMJ.2001;322:780- 782

[40]. Kennedy PG, Mitchell DM, Hoffbrand BI. Severe hyponatraemia in hospital inpatients. BMJ.1978; 2:1251- 1253 